\title{
Las lenguas del animal. Fábulas de la pobreza y la vida precaria ${ }^{1}$
}

\author{
The animal's languages. \\ Fables of poverty and precarious life
}

\author{
NURIA GIRONA FIBLA ${ }^{a}$ \\ ${ }^{a}$ Universidad de Valencia, Facultad de Filología, Traducción y Comunicación, España. \\ Correo electrónico: nuria.girona@uv.es
}

\begin{abstract}
Este artículo se propone indagar alrededor de la representación literaria del animal y la imaginación política del presente, en tanto el paradigma de la "vida humana" constituye un límite biopolítico que establece qué vidas merecen tal calificación y qué vidas quedan al margen de ese reconocimiento simbólico y jurídico. A partir de "Yzur" (1096) de Leopoldo Lugones, el artículo muestra cómo funciona esta "máquina antropológica" que en su captura de lo viviente impone una lógica de dominación y explotación. En contrapunto presenta el relato "Como un león" (1967) de Haroldo Conti, el poemario El duelo (2010) de Igor Barreto y el cuento "Hambre perra" (2009) de Lina Meruane como espacios de fabulación en donde la figura del animal no se presenta como el negativo de lo humano sino como una variación que disuelve sus límites y suspende el orden de distribución de los cuerpos previsto por la biopolítica.
\end{abstract}

Palabras claves: biopolítica, animal, precariedad, Lugones, Conti, Barreto, Meruane.

This essay aims to inquire about the literary representation of the animal and the political imagination nowadays, as the "human life" paradigm represents a biopolitical boundary that states which lives deserve such status and which lives are left out of such symbolic and legal recognition. Starting with "Yzur" (1096) by Leopoldo Lugones, the essay shows how this "anthropological machine" works, which in its capture of the living imposes a logic of domination and exploitation. In contrast, it presents the short story "Como un león" (1967) by Haroldo Conti, the collection of poems El duelo (2010) by Igor Barreto and "Hambre perra" (2009) by Lina Meruane as fictional spaces where the figure of the animal is not presented as the opposite of the human one but as a variation that blurs its boundaries and suspends the established biopolitical order of the distribution of the bodies.

Key words: biopolitics, animal, precariousness, Lugones, Conti, Barretto, Meruane.

\footnotetext{
${ }^{1}$ Esta investigación se ha desarrollado en el marco del proyecto de investigación competitivo con Ref. RTI2018093523-B-I00, del Ministerio de Ciencia, Innovación y Universidades.
} 


\section{INTRODUCCIÓN}

Dura poco la muerte en esos lugares señalados.

Igor Barreto

"Dura poco la muerte", poetiza Igor Barreto (2014: 337) y no se refiere solo a la muerte instantánea sino a la intrascendencia que tiene morir en algunos lugares del mapa contemporáneo. La muerte que dura poco borra la vida que la precedió, la hace desaparecer con prontitud, la vacía de humanidad. Porque si la muerte no deja rastro, tal vida no merece la consideración de humana. "Algunas vidas valen la pena, otras no", observa Judith Butler (2006: 16) en relación con esta distribución diferencial del dolor que hace merecedores a unos de la expresión del duelo tras su muerte e ignora a otros. Una consideración que produce y mantiene ciertas concepciones excluyentes de lo normativamente humano: “¿Qué cuenta como vida vivible y muerte lamentable?” se pregunta Butler (2006: 17) cuando dura tan poco la muerte.

En las páginas que siguen partiré por tanto de la diferencia entre lo que es reconocido como humano y lo que queda fuera para indagar sobre la propiedad de la vida humana en todo su alcance: a quién se le atribuye y qué la califica. A partir de esa línea divisoria que separa políticamente lo humano de lo que no lo es, exploraré la distancia que se establece con el animal en ciertas representaciones literarias contemporáneas. Voy a tomar el animal como un límite que ausenta la humanidad de ciertas vidas, un límite biopolítico que captura la vida para mejor gobernarla ${ }^{2}$.

En ese sentido me interesa analizar la figura del animal, los cuerpos que adopta, el lenguaje que lo construye, el borde que lo significa. El tropo de la bestia implica siempre un modelo de mundo y una forma de compartimentar la vida, compone una retórica que suplanta un cuerpo por otro y que con frecuencia se convierte en tópico despectivo. "Morir como un perro", decimos, al nombrar el abandono de una muerte indigna de nuestra condición y la comparación se carga de política, en el particular reparto de cuerpos y formas de vida que enuncia. Ahí donde emerge el animal se suspende la silueta humana y con ella su marco de reconocimiento simbólico y jurídico ${ }^{3}$.

El bestiario que incluye nuestro lenguaje despliega todo un catálogo de asociaciones fijadas que hacen del animal un topos, es decir, un espacio de significaciones predeterminadas,

\footnotetext{
2 "Durante milenios, el hombre siguió siendo lo que era para Aristóteles: un animal viviente y, además, capaz de una existencia política; el hombre moderno es un animal en cuya política está puesta en entredicho su vida de ser viviente" (Foucault 1987: 173). En este contexto, "habría que hablar de «biopolítica» para designar lo que hace entrar a la vida y sus mecanismos en el dominio de los cálculos explícitos y convierte al poder-saber en un agente de transformación de la vida humana" (Foucault 1987: 173).

${ }^{3}$ En su concepción de la nuda vida y el homo sacer, Agamben se refiere a este umbral más allá del cual la vida deja de revestir valor jurídico y puede ser suprimida sin cometer homicidio (2010: 176-7).
} 
fuertemente consolidadas en nuestra cultura. Este topos constituye un límite antropomórfico investido de valores, que se erige como una norma de lo humano que califica y descalifica formas de vida.

El espacio de la ficción permite habitar este lugar común de otra manera, incluso permite habitar en el animal al modo de Gregorio Samsa según escribió Kafka. La condición de la fábula suspende el orden de distribución biopolítico imperante con la emergencia de lo monstruoso o lo anómalo, abre el espectro de lo viviente ${ }^{4}$. El límite de la no-persona ${ }^{5}$ o de los cuerpos que son irreconocibles como tales se vuelve campo de exploración para problematizar la política y las formas de lenguaje establecidas.

Me guían en este recorrido las palabras de Agamben para "aprender a pensar, muy de otro modo, al hombre como lo que resulta de la desconexión de esos dos elementos [lo humano y lo animal], e investigar no el misterio metafísico de la conjunción, sino el misterio práctico y político de la separación" (2006: 35). ¿Qué define, en consecuencia, lo humano, la persona? Es siempre el lugar -y a la vez, el resultado- de divisiones y cesuras incesantes, contesta Agamben. De ahí la guía: "trabajar sobre estas divisiones, preguntarse de qué modo - en el hombre- el hombre ha sido separado del no-hombre y el animal de lo humano" (2006: 35).

La historia de estas cesuras es una historia de dominaciones. "Yzur" (1906), de Leopoldo Lugones (Argentina, 1874-1938), las reúne en la ficción de un científico obsesivo que enseña a hablar a un mono. Publicado en Argentina a comienzos del siglo XX, el cuento me servirá para establecer las pautas de mi exposición y un contrapunto con otras fábulas más recientes que analizaré más adelante.

La fantasía científica de Lugones remite a las polémicas darwinistas de la época que permiten al narrador formular una curiosa hipótesis regresiva: si el hombre es un mono perfeccionado, el mono es un hombre degenerado. Según este presupuesto, los monos fueron hombres que por una u otra razón dejaron de hablar, descendiendo al escalón del animal. No hablan, añade el narrador "para que no los hagan trabajar" (1987: 156).

Me detengo en el armazón científico del cuento porque funciona como una estrategia de verosimilitud y de autoridad muy blindada por parte del narrador, que se demora en ella a riesgo de entorpecer el relato. La ciencia y la lengua separan al humano del animal, en una distancia que fundamenta su superioridad y legitima el experimento. Así

\footnotetext{
${ }^{4}$ Apunta Gabriel Giorgi que ciertas ficciones contemporáneas en América Latina plantean una disociación entre la "persona" y la "cosa viviente" como problema a la vez estético y político: "entre el «sujeto" (el individuo, la persona, el yo, etc.) y ese resto corporal, biológico, ese "ser viviente" sin cualificaciones en el que, por factores que involucran dimensiones políticas, se convierten" (2014: 42).

${ }^{5}$ Es justamente el dispositivo de la "persona" el que para Esposito, en lugar de unificar la brecha entre hombre y ciudadano produce una separación profunda entre derecho y vida: "ella es la que, desde el punto de vista jurídico, separa a la vida de sí misma, hace de la vida el terreno de una decisión previa entre aquello que debe vivir y aquello que, por el contrario, puede morir, porque es una mera cosa en manos de quienes, dado su estatus ontológico superior, son los únicos calificados para disponer de ella” (2009: 143-4).
} 
opera la "máquina antropológica" a la que alude Agamben (2006: 69-76) ${ }^{6}$, mediante una segmentación que divide y verticaliza formas de vida, según un poder que decide dónde colocar la cesura, un poder que rige en esta historia de disciplinamiento y tortura.

Con el pretexto de valorar la excelencia de este "sujeto pedagógico" (Lugones 1987: 158), el narrador compara al mono con un negro, con un mulato triste, varias veces con los nińos, con un sordomudo... Compone así una escala de degradación de la vida que se resume en la frase con la que comienzan los ejercicios de adiestramiento: "Yo soy tu amo", a la que sigue: "Tú eres mi mono" (1987: 163). Lugones reúne así, en el lugar del animal, la historia de la dominación colonial, de la selección eugenésica, de la limpieza étnica, de la biomedicina, de todos esos anacronismos que la ciencia ficción hace posibles en un mismo tiempo.

Podemos considerarlo sencillamente un cuento sobre la ciencia deshumanizada pero el sintagma pivota sobre lo mismo: ¿qué define lo humano? Si seguimos a Lugones, la cuestión se plantea a partir de una oposición, por eso resulta relativamente sencillo entablar los dos lados de la ecuación y observar cómo los cruza: el científico animalizado, el animal humanizado, el negro reducido a bestia, el mono sin lenguaje, el amo de la lengua, etc. El esquema retórico traduce con claridad esta concepción de lo humano, una cuestión que se complicará en el corpus que analizaré más adelante, pero que entabla las bases de lo que podríamos considerar una "retórica del animal". Quiero decir que el lenguaje del cuento y su lógica responden a una distribución de cuerpos y vidas calificadas muy diáfana: lo que es del hombre (el logos, el lenguaje, la ciencia, el poder), lo que es del animal (que carece de lo anterior), aunque se contagien o se inviertan en la narración, no importa, porque siempre la confirman. Este es uno de los motivos por lo que el mono debe morir al final del cuento. Porque tanto el hombre, que ha enloquecido, como el animal, que ha hablado, han atravesado un límite insoslayable. Límites y oposiciones inamovibles para Lugones, que siente como una amenaza tanto el avance científico como el inmigratorio de los procesos modernizadores y urbanizadores argentinos de principios de siglo XX.

Tal y como anota Julio Ramos: "el delirante lingüista establece una correlación entre la lengua, la sociabilidad y el trabajo: hablar, entrar al territorio regulado por la ley de la lengua, es concomitante a la incorporación del cuerpo a la fuerza laboral" (1996: 4). No olvidemos, como vimos, que el vínculo entre lengua y trabajo desencadena el experimento y define el estatuto del amo.

Más allá de las pugnas nacionales sobre la pureza de la lengua y el impacto de la inmigración en la que Ramos inscribe su lectura, resulta llamativo que lo que el aprendizaje lingüístico del mono parece garantizar no es su humanidad sino el reconocimiento sumiso de su dueño. De hecho, en el momento de morir, le pone palabras a ese sometimiento:

\footnotetext{
${ }^{6}$ Como el animal, la recurrencia al símil de la máquina define el contorno de lo humano: el "dispositivo de la persona" de Espósito (2009) retoma la "máquina deseante" de Deleuze y Guattari; la "máquina zoopolítica" que propone Giorgi sirve para pensar los animales en las producciones literarias; el "animal-máquina" de Derrida reúne "en un solo sistema la no-respuesta, el lenguaje que no responde porque está fijo o fijado en la mecanicidad de su programación y, finalmente, la carencia, el defecto, el déficit o la privación” (2008: 107).
} 
"Amo, agua, amo, mi amo" (Lugones 1987: 165), exclama, lo que lo convierte en esclavo prácticamente sin dejar de ser animal. Solo disfruta de su condición humana por unos minutos y lo hace en la opresión 7 . Esa es la clave de su amaestramiento para la explotación, inculcarle su alienación, que sepa que hasta para beber depende de su amo.

Por unos minutos el aprendizaje impuesto por el científico triunfa. Pero con el advenimiento del lenguaje y este reconocimiento, que también es la conciencia absoluta de su desposesión, sobreviene la muerte. Quizás provocada por el suplicio al que ha sido sometido o quizás por no soportar lo que le depara el mundo humano. Lugones ensaya con "Yzur" una lengua para el subalterno, para ponerlo a trabajar y lo lleva a la muerte. Solo así cobra sentido en la economía narrativa el punto de partida del relato.

Desde esa perspectiva se entiende el proceso de aprendizaje que describe para imponer la performance de lo humano (sus gestos, sus conductas, su mímica). El experimento pretende producir un sujeto, pero no un sujeto cualquiera, un sujeto para trabajar, doblemente sujetado a la gramática y al patrón. El adiestramiento con el que doblega al mono explora la captura de lo viviente y experimenta un proceso de subjetivación que garantice la internalización del poder.

Yzur es un mono humanizado tanto como un esclavo animalizado, esa es la condición para asegurar su explotación. Por tanto este umbral animal es el requisito indispensable de desaparición de la humanidad del subalterno, que solo debe hablar para trabajar o morir.

¿Qué aparece y qué se ausenta en la oposición humano/animal del cuento? Aparece el poder de experimentar y de esclavizar. Quien tiene el poder de la ciencia tiene el poder del lenguaje, el poder de poner a trabajar e incluso el poder de "hacer vivir y dejar morir" con el que Foucault (2000: 218) definió el surgimiento de la biopolítica. Es el poder de humanizar al mono y de esclavizar al humano, de hacer desaparecer ya no la vida animal sino cualquier rastro de vida, que es lo que se va con la muerte del mono. Es justamente el dominio para establecer estas cesuras lo que pone en juego el poder biopolítico. El elemento fundamental de la "máquina antropológica" es la zona de indeterminación que se forma en su centro, como un estado de excepción que constantemente debe ser refundado: "Como todo espacio de excepción, esta zona está en verdad perfectamente vacía, y lo verdaderamente humano que debe producirse es tan solo el lugar de una decisión incesantemente actualizada, en la que las cesuras y sus rearticulaciones serán siempre deslocalizadas y desplazadas" (Agamben 2006: 76).

Por tanto el análisis que va a continuación toma como el eje la lengua y el trabajo, todo aquello de lo que carece el animal de Lugones y todo aquello de lo que lo desposee. Las ficciones y fabulaciones seleccionadas pueden leerse como historias que ensayan sujetos, animales y lenguajes. Mi intención no es tanto ofrecer una panorámica sino recalar en algunas producciones contemporáneas que, pese a la variedad de estilos y procedencia,

\footnotetext{
${ }^{7}$ Aunque la posibilidad de burla del mono está presente en todo el relato, como una manera de medir su resistencia, lo cual es motivo de paranoia por parte del científico. De hecho lo primero que aprende, en sus ejercicios de fonación, es a sacar la lengua.
} 
pueden inscribirse en lo que antes llamaba "retórica del animal" en su representación biopolítica de la precariedad.

En el primer apartado que sigue presento un relato de Haroldo Conti (Argentina, 1925 - desaparecido, ¿1976?) que toma como referente la figura de un león para fundamentar una retórica de la pobreza, la de los habitantes de una villa en el Buenos Aires de finales de los ańos 60. Todo aquello que inviste el tropo del animal sirve para representar las privaciones materiales de la miseria, pero también para confrontar una concepción hegemónica que la había vaciado de vida.

En los apartados siguientes la figuración del animal, ya no se presenta en torno a las carencias de la miseria, sino a una necesidad básica: el hambre. Tanto el poemario de Igor Barreto (Venezuela, 1952) como el cuento de Lina Meruane (Chile, 1970) giran en torno a una desposesión extrema y los efectos de las políticas neoliberales más allá del empobrecimiento. En estas composiciones el límite animal es el límite de lo precario, de "las condiciones de vida, de la vida como algo que exige unas condiciones para llegar a ser una vida «vivible» y, sobre todo, para convertirse en digna de ser llorada" (Butler 2010: 42). Su precariedad se abre a su vez como condición compartida de la vida humana, por no decir, "como una condición que vincula a los animales humanos con los no humanos" (Butler 2010: 30).

\section{Como UN ANIMAL}

El relato de Haroldo Conti, "Como un león" (1967), está narrado desde la perspectiva de Lito, un nińo que ha nacido en una de villa de Buenos Aires, que cuenta cómo transcurre su vida cotidiana. El cuento despliega la mirada de Lito sobre ese espacio a la par que este describe a sus pobladores y valora las posibilidades que le depara el futuro: sopesa los peligros de quedarse o salir de la villa, recurre a referentes cercanos que le sirven de modelo, busca un sentido a su experiencia de niño. La trama tiene mucho de relato de iniciación, en el que el final de la infancia coincide con una acción delictiva y el abrupto ingreso en el ámbito de la sexualidad.

La expresión "como un león" surge en primer lugar de su visión del espacio, con las primeras luces del amanecer con las que se inicia el cuento, en el tiempo en el que todo está por comenzar. Pero "como un león" alude también a un ideal de realización, a una identificación que concretan la posición vital del niño. La comparación se articula en torno a estos dos ejes que organizan el relato, el espacio y el personaje.

Respecto al espacio, la villa se sitúa junto al puerto, alrededor de las fábricas y las vías ferroviarias que dieron trabajo en el pasado a sus habitantes, restos industriales y basura entre los que se pasea Lito y proyecta sus fabulaciones, indicios del fracaso del auge modernizador que apuntaba el cuento de Lugones. Los barrios pudientes se divisan a lo lejos en su mirada ("Mientras tanto los grandes tipos duermen allá lejos en su lecho de rosas", Conti 2003: 159). 
El lugar, por su ubicación, resulta fácilmente reconocible ${ }^{8}$, a pesar de la continuidad con el trazado urbano, Lito lo percibe alejado y separado, como un adentro frente a un afuera apartado, representado por el centro de la ciudad, en correlación con su presente y su futuro. Su mirada también lo registra como un organismo vivo y dinámico: "Las villas cambian y se renuevan continuamente. Son algo más que un montón de latas. Son algo vivo, quiero decir. Como un animal, como un árbol, como el río, ese viejo y taciturno león. Como un león, justamente" (2003: 157).

La villa tiene vida propia, en el flujo de transformaciones que encarna y en el vigor de un melancólico animal. Pero antes de revisar de dónde proviene esta melancolía, me detengo en la descripción que Lito hace de sus habitantes, que enfoca por separado, de tal manera que, así vistos, "parecen otros tipos". La individualidad viene dada por los nombres de cada uno y por la variedad de sus actividades laborales: lustrar zapatos, vender periódicos, abrir la puerta de los coches en el barrio del Retiro, escarbar en la basura; son "formas de ir tirando" (2003: 159), dice Lito. El padre de Tulio trabaja en la dársena, otros salen a la fábrica en hilera cada mańana. Lo que destaca en este medio es que sus habitantes no son desocupados, aunque la delincuencia empieza a despuntar, así como el trabajo informal de los hijos frente al asalariado de los padres. Lo que capta la mirada de Lito es el inicio de una desintegración laboral, familiar y generacional. Algunos de los amigos han estado ya en la cárcel, la policía ha matado a su hermano de una paliza, Tito ha muerto atropellado impunemente en la avenida (en la frontera con la ciudad). De ahí proviene el cariz melancólico del animal, de ese organismo vivo que mantiene aún parte de su fuerza.

En la lucha diaria por la supervivencia surge la consigna: "Levántate y camina como un león" (2003: 153) que viene de la memoria del hermano y del consejo de no seguir sus pasos. El uso del mismo símil para describir a la villa y a sí mismo "indica que el espacio y el cuerpo conforman una unidad" (Forcadell 2009: 69). La frase remite al aprendizaje de la fuerza y la hombría, a la jerarquía del más fuerte que empieza a imperar dentro y fuera del asentamiento. Pero también al orgullo de pertenencia a un origen signado por la villa, por una comunidad y por una clase.

"Como un león" es la solución poética que halla Lito cuya identificación animal le permite reinventarse. Es fundamentalmente el contrapunto creativo de quien se sabe mirado compasivamente. Al referirse a quienes pasan en coche por la avenida y esgrimen esta mirada, afirma: "Nos tienen lástima. Pero los que merecen toda la lástima del mundo son ellos y no creo que les alcance. No les envidio nada. Mal o bien nosotros estamos vivos. Eso es algo que ellos no saben y mejor así porque si no se nos echarían encima" (2003: 164).

La vida que esta mirada piadosa ignora es la que Lito es capaz de ver bajo el "montón de latas", de la que él mismo participa: "Levanto la cabeza y respiro hondo el

\footnotetext{
${ }^{8}$ Puede identificarse con Villa 31, uno de los asentamientos de inmigrantes y obreros más emblemáticos de Buenos Aires, situado muy cerca del centro urbano. Se trata, como apunta Saítta, de una elección acorde con los posicionamientos ideológicos de Conti y las experiencias de Norman Brisky con el "Teatro villero" (2006: 98).
} 
áspero alimento del río. Entonces todo eso se me mete en la sangre y me siento vivo de la cabeza a los pies, como un fuego prendido en la noche" (2003: 157). Ese contagio le permite también transfigurar la muerte del padre y del hermano no solo para sentirlos cercanos sino para no vaciarlos de vida, de vida pobre, de "esa vida rońosa, como la llaman" (2003: 155), afirma. La comparación con él león mina entonces la relación entre pobreza y conmiseración. También la criminalización de la pobreza por parte de la maestra, que termina por llamar a los chicos "degenerados".

En este marco, la villa es un adentro y un "nosotros" marcado por la exclusión social y por quedar fuera del circuito del trabajo y del acceso a los bienes de consumo, cifrados en la fascinación que el niño siente por los automóviles (como el padre muerto sentía por los trenes) y que, sin embargo, percibe como una amenaza (un auto atropella sin mayores consecuencias a Tito, el hermano se enseñoreaba con un coche de dudosa procedencia, en un coche un homosexual intenta forzarlo) ${ }^{9}$.

La narración de Conti marca una cesura en los modos de representación de la pobreza respecto a la generación precedente de escritores, el grupo de Boedo, que combinaba el "realismo piadoso" con el sentimentalismo, el "hipernaturalismo de los manuales médicos" con una "mirada del diagnóstico y la denuncia" ante la miseria trasfigurada de monstruosidad (Sarlo 1988: 199-205). Desde esta perspectiva tanto la escritura del relato como el potencial retórico que Lito revela suponen una novedosa propuesta en el paradigma de la representación realista, especialmente por su exploración alrededor de una imaginación que es política y poética a la vez ${ }^{10}$.

"Como un león" no solo viene a alterar los valores de esta representación, sino que propone una retórica inaudita para los pobres, en la posibilidad del manejo de un lenguaje inapropiado para ellos. El símil animal forma parte de la poetización, no de la pobreza sino de las posibilidades de transformación de Lito, de reinvención, como exponía antes. Sin duda el autor habla a través del nińo, pero su estilo intenta aprehender ese universo ingenuo y prometedor de la infancia en el que todo está por estrenar. En ese lugar se emplaza cuando Lito dice que piensa en todas las cosas de la vida "como si estuviera muerto o bien a punto de nacer" (2003: 154). Si acaso es la infancia la que se idealiza, no la pobreza, porque el texto no elude ni estetiza sus carencias.

Como en el cuento de Lugones, Conti narra un proceso de subjetivación, en este caso, de un sujeto sometido a condiciones precarias, pero a diferencia de sus predecesores, no obtura ni su capacidad de pensar ni de imaginar. En varias ocasiones el personaje insiste

\footnotetext{
${ }^{9}$ Este episodio funciona como un anticipo de los peligros del "afuera" de la villa, de la avidez consumista y sexual que empieza a invadirla y que también amenaza el aprendizaje de la hombría en la que el cuento insiste. Un episodio de violencia sexual que se articula en términos de clase, en términos de género y en términos animales: frente al depredador, Lito logra escapar porque se levanta y corre como un león.

${ }^{10}$ No solo de la generación precedente sino también de sus coetáneos (Saítta 2006: 98), que priorizaron la representación documentalista, como Villa Miseria También es América (1957), del periodista Bernardo Verbitsky (que difunde el término "villa miseria" para este tipo de emplazamientos) y Los hijos de Sánchez (1964), de Oscar Lewis (que establece el concepto antropológico de "cultura de la pobreza").
} 
en ese gesto reflexivo que lo caracteriza, en ese intento por pensar de otra manera y en ese pensamiento que nadie le puede ni adivinar ni robar.

De la misma manera, la lengua de Lito escapa del registro sociolingüístico asociado con los de su clase y con ella puede escapar de la fatalidad determinista o de la nada que se le supone. Esta cuestión está enfatizada en el texto, en las opciones que le presenta su entorno: frente al lenguaje previsible de la madre ("Cuando se le da por hablar no termina nunca. Yo sé cuándo está por hablar y además sé lo que va a decir”, 2003: 158), frente a la ausencia de lenguaje de Tulio (incapaz de expresarse incluso cuando se enfurece) o en el dominio del lunfardo que ostenta.

En definitiva, Conti erige un imaginario de la pobreza en la posibilidad misma de Lito de imaginarse de otra manera, en el potencial creativo que le permite transmutar lo que percibe en un león. Pero no se queda aquí.

Entre las pérdidas y la explotación, Lito/Conti ensaya un lenguaje antes de abismarse en el peligro del mundo de los adultos, entre el peligro de la vida delictiva que lo aguarda en la ciudad y la inminencia del deterioro en la villa. Dos espacios, dos lenguajes y una vida animal que se le echa encima:

Trato de aprender lo que puedo pero la mayor parte del tiempo la cabeza se me vuela como un pájaro. Vuela y vuela, cada vez más alto, cada vez más lejos. No es para menos. La vida zumba y se sacude ahí afuera y yo estoy metido aquí dentro esperando el día que salga y salte sobre ella como mi hermano, es decir, como un león. Cada vez lo entiendo mejor (2003: 162).

El león personifica las aspiraciones de Lito y el impulso que debe encarnar ante los ataques que le esperan. Ya no responde al mundo animal porque encarna una vida viviente, podríamos decir, alistada junto al árbol, el río (los términos que designaban la villa), la vida interior y la fiereza de aquella que la asalta, y que él debe ganar. De pronto el binomio que Lugones asentaba se complica, se disuelve el dualismo que separa el orden animal y el humano, las significaciones que lo fijan y que no se capturan como una inversión exacta. Pero la recurrencia se plantea en términos de similitud, lo cual mantiene intacto cierto antagonismo. El nexo "como" indica parecido, semejanza que no se completa en la plenitud, que no suplanta un término por otro en su equivalencia. El león es figura de otra cosa pero no la figura de por sí en esta retórica. "Como" mantiene todavía a distancia la diferencia animal y la diferencia de quien quiere hablar como un niño aprendiz de animal.

\section{LA LÍNEA DE LA POBREZA}

El tropo del viejo león le sirve a Conti para dar cuenta del complejo de dinámicas espaciales, sociales y políticas que definen el espacio de la villa sin achatarlo, desde los lazos 
de vecindad, parentesco e identidad que contiene hasta el límite de la avenida o las vías ferroviarias que la separan de la ciudad en el trazado urbano.

Ahora bien, no pasa desapercibido, en el contexto del relato, el tipo de pobreza al que hace referencia y los detalles en los que se detiene. La insistencia del hermano de Lito para que acabe la escolarización o el hecho de consignar los alimentos que toma a lo largo del día aluden a un nivel de necesidades que todavía quedan cubiertas en ese espacio de exclusión. Lo que separa a Lito de los "grandes tipos", como dice, es que no tiene un coche, ese objeto lujoso al que aspira. En el cuento, la pobreza se define por la escasez de recursos que no permiten acceder, como planteaba, a ciertos bienes de consumo. A finales de los años 60, la carestía que retrata el escritor parece más en consonancia con el empobrecimiento de las clases medias de los años 90 que con la extrema pauperización de las villas en la actualidad o la expansión de los enclaves de pobreza en el mundo contemporáneo.

Dos consideraciones quisiera apuntar al respecto antes de seguir, una referida a la manera de abordar la pobreza y otra a sus representaciones literarias en las fábulas que siguen. La propuesta de Conti nos alerta sobre las limitaciones de conceptualizar la carestía a partir de parámetros exclusivamente económicos. Como sugiere Javier Auyero, en su lectura de Parias urbanos. Marginalidad en la ciudad a comienzos del milenio, de Louis Wacquant, "llevar a Wacquant a la villa sugiere entenderla como una relación entre la economía, el descuido estatal y la acción de los actores políticos dentro y fuera de la villa" (Auyero en Wacquant 2007: 23). Porque la consideración de una "línea de pobreza" que la equipara con bajos ingresos "termina oscureciendo las características específicas de los procesos de marginación, su variedad demográfica y social o las variantes de las circunstancias que llevan a la exclusión social" (Auyero en Wacquant 2007: 27).

En este oscurecimiento se deslizan los parentescos del orden animal que asaltan nuestro lenguaje y ciertos imaginarios de la pobreza. Sin embargo ya vimos cómo Conti perfila un entrecruzamiento de categorías que complica su categorización, en lo que Yelin denomina "giro animal" (2015: 148). Un cambio en torno al paradigma de la animalidad que recorre la filosofía en las últimas décadas, con el cuestionamiento de otra línea divisoria lo humano, como antes expuse, y un cambio de dirección que afecta a los modos de representación literaria. Yelin alude a "la caída de la metáfora animal" (2015: 148) que ya no contribuiría a la reproducción de un determinado valor simbólico de sus figuraciones (basado en la simetría y en la alteridad constitutiva que narrativizaba Lugones), sino que, por el contrario, sería artífice de su disolución.

Este cambio en el paradigma de la representación imposibilita una relación de equivalencia -fundamental en la construcción metafórica- porque uno de los polos de la comparación se multiplica y, de ese modo, invade y desvirtúa la frontera establecida con su contrario: “¿Cómo podrá un término valer por otro si resulta que existe una indisoluble articulación, si en lugar de pensar en una línea divisoria comenzamos a vislumbrar una cesura que, como afirma Giorgio Agamben, tiene lugar al interior de lo humano?" (Yelin 2015: 148). Esa desarticulación de lo viviente que sugiere Conti al final de su relato y que terminará de desencajarse en las siguientes fabulaciones. 


\section{Sacar el animal del canto}

"En la caverna de la boca ya no veo palabras, sólo hambre" escribe Igor Barreto en El duelo (2014: 308). Los versos aluden tanto a la imposibilidad de representación del hambre como al hambre que deja sin habla. El poemario se organiza alrededor del asesinato de un caballo para comerciar y consumir su carne, que se relata en prosa al comienzo del libro. Cada una de las composiciones que siguen elaboran, en el registro poético y narrativo, esta escena. Cada una de ellas indaga alrededor de la muerte de los caballos y del hambre que lleva a la necesidad de matarlos, un hambre expansiva, "que rompe, destroza, corta, quiebra” (2014: 308), que agiganta la boca y fractura el verso:

un árbol entero

podría colocarse

en ella (2014: 365).

Pese a lo que esta síntesis apunta, el poemario no compone ni una fábula ni una alegoría ni las correspondencias entre lo natural, lo animal y lo humano pueden establecerse fácilmente ni en la misma dirección, más bien actúan como vectores que disparan sentidos, movilizan cesuras y desestabilizan espacios de contención. Inclusive la subjetividad de quien habla, que propone "ensancharse / y sacar el animal / del canto", en lo que Derrida -quizás Conti también- consideraría un pensamiento del animal: "si lo hay, depende de la poesía" (2008: 22). Este pensamiento emerge, no como una dimensión exterior o extrańa del hombre, sino como una interioridad que se expande en el ejercicio del canto poético, en una lengua cuyo desvío se aleja del habla humana, a partir de un sujeto que se sabe habitado por el animal y por un deseo impersonal ("ensancharse") que evite su captura ("sacar el animal del canto").

En la ambigüedad que se cierne entre el canto del animal y el canto al animal transita esta poética que modula vida y palabra. No se trata pues de "restituir la palabra" al animal sino "de acceder a un pensamiento, por quimérico o fabuloso que sea, que piense de otro modo la ausencia del nombre o de la palabra; y de otra manera que como una privación" (Derrida 2008: 66), como exponía anteriormente. Es a partir del caballo precisamente ("aquella mudez/ sin nombre") que Barreto piensa los límites del lenguaje humano, así como los vínculos con lo viviente animal. Ni devuelve su voz al caballo ni habla por él, antes bien sus carencias desarticulan los predicados de la vida y la palabra humana.

Porque si por un lado la relación con el caballo define tanto un afecto como una forma de vida en el llano venezolano (en su cuidado y en su doma), la condición humana queda de lleno "afectada" por la singularidad de este animal, cuya belleza y lealtad el poemario destaca, especialmente en lo referido a su incondicionalidad. Estas cualidades no se proyectan, insisto, como una humanización del caballo, lo que volvería a incidir en un dualismo que lo asimile a lo mismo; al contrario, se trata de no convertir la asimetría en una oposición de absolutos, de ensayar una diferencia que no se sustente exclusivamente en 
el dominio del caballo y no lo reduzca a su utilidad. Más que una oposición se formula un campo de relaciones transitivas e intransitivas, entre la reciprocidad de un "modo de estar" con el animal y la inmanencia del "modo de estar" del animal.

Hasta aquí lo que atañe al canto dirigido al caballo, a lo que convocó su presencia. Aunque es su ausencia en realidad lo que se canta, el hueco que deja su muerte que, a su vez, ahueca la condición humana. En este sentido la pérdida del caballo revelará hasta dónde sostenía esa existencia humana y hasta dónde queda "afectado" el contorno de la especie. La falta del animal pone de relieve la falta humana, es decir, sus carencias, sus fallos, su fragilidad.

La muerte del caballo remueve estos límites, pero ante todo pone de relieve la lógica sacrificial que los funda, la misma que exponía el cuento de Lugones y que precisa de la captura de la animalidad como captura de lo viviente para asegurar superioridad y poder. El comercio con la carne que apunta el poemario convierte al caballo en vida capitalizable, en carne hecha mercancía y en cuerpo disponible para la explotación, en vida sacrificable, en definitiva. De la misma manera el abandono de sus restos acusa un límite biopolítico, aquel que decide qué vidas son dignas de protección y cuáles prescindibles. De este modo la sangre que deja su apresurado enterramiento se extiende a "un país con la forma de una mancha de sangre" (2014: 314), a una zona de indeterminación, de vida politizada, ya no animal ni humana, tan solo vida desnuda de todo atributo.

El sacrificio del animal instala la violencia entre los habitantes de este paisaje poético, a la vez que deja al descubierto las vidas expuestas a la voracidad del capital y la vida expuesta a la pérdida, un común que queda más allá de la persona. Todo el poemario compone, como indica el título, la expresión dolorosa de una ausencia. Pero la elegía no da cuenta solo de una herida subjetiva, sino que otorga una inscripción simbólica a la muerte del caballo y una restitución a lo que fue su vida, al común de la vida que instauró. El duelo implica el reconocimiento de una vulnerabilidad mutua (de quien se va y de quien queda), de la exposición a la muerte, intrínseca a toda condición viviente. Barreto reconduce así el repliegue narcisista de la melancolía, propia del duelo, a una expresión de lo común, de lo que hace comunidad, que no parte de la dicotomía con el animal sino de lo que este vela, del animal como resto de la vida humana.

Es este común el que desplaza la demarcación entre lo humano y lo animal. Desde la exploración de un lenguaje afín a la continuidad afectiva o la vulnerabilidad compartida, la vida animal emerge en esta obra como un campo expansivo que indaga una "proximidad que es a la vez una zona de interrogación ética y un horizonte de politización" (Giorgi 2014: 12), clave para que los procesos biopolíticos de precarización no gobiernen la subjetividad ni modulen el valor de la vida.

En todo caso, uno de los versos finales retoma de nuevo la imposibilidad de representar la experiencia del hambre porque "lo real ha invadido lo real... / y no hay escapatoria" (2014: 357, cursivas del autor). Entre el enriquecimiento y la necesidad, el hambre se hace animal, de la boca "sale un algo cuadrúpedo: / el errante caballo / pordiosero" (2014: 325). En este "real" se lee un agujero que ya no deja hueco a su realidad porque sus efectos intolerables lo 
recubren todo. El hambre es lo imposible del lenguaje. El poemario ensaya una lengua para hablarla en el umbral que deja el animal ${ }^{11}$.

\section{El hambre animal}

Este núcleo de lo real es el que también aborda el cuento "Hambre perra” (2009), de Lina Meruane, a partir de la narración de un estado, de un estado animal que pone a funcionar el lenguaje de otra manera, difícilmente resumible en su anécdota, por otro lado, mínima.

Digamos, para comenzar, que el cuento se funda también en el hambre, como el poemario de Barreto. En esa necesidad básica de la subsistencia que no distingue entre especies, que se vuelve en sí misma salvaje, aunque en realidad su codificación escapa a la oposición entre lo humano y lo animal. En este apremio urgente se encuentran la protagonista y su perra, la Negra, sin poder distinguir el hambre de una y de otra, y confundiendo su propia naturaleza. El hambre despersonaliza, deshumaniza, desnaturaliza, como se quiera considerar, porque el cuento opera con ese "des" en el que leemos la zona de indistinción que poetizaba Barreto, de vida desnuda. Una indistinción entre vida humana socialmente reconocible y vida "meramente biológica", despojada de las marcas que la vuelven objeto de protección y reconocimiento en el orden biopolítico.

Así como no se distinguen los cuerpos de la protagonista humana y de la protagonista animal tampoco se diferencian las crías de sus amas ni la carne que las alimenta ni la leche que las nutre. Negra es la perra, la madre, la noche y el hambre; perra es el hambre, pero también el término que designa a la prostituta, a la madre de la narradora y a ella misma, una correlación que el texto sugiere y con la que desvela hasta dónde la feminidad se ha construido en el lugar de la alteridad animal. En ese sentido, el relato también lleva a un límite insoslayable la consideración de la maternidad como principio de vida.

Estas son solo algunas de las violentas intersecciones y continuidades que traza el cuento, en donde se disuelven las cesuras de lo viviente, que caen con el hambre y que vengo describiendo. No se trata nuevamente de una metáfora ya que el relato la aborda desde una dimensión física que atraviesa los cuerpos, desde una materialidad radical. Si Conti focalizó la pobreza en la ausencia de recursos (no tener trabajo, no tener coche, no tener dinero), Meruane invoca su carencia a partir del hambre que remueve al ser desde las tripas y desde su condición de cuerpo de mujer. Como la boca agigantada de Barreto, aquí el hambre lo devora todo.

Porque lo que aquí se figura como "hambre perra" es efectivamente, lo real (no la realidad) del hambre. Esa punzada que ya no se puede nombrar y cuya voracidad

\footnotetext{
${ }^{11}$ Un umbral definitorio de la poética de Barreto, según Saraceni, para "capturar con la palabra lo que se juega en esa zona de indeterminación de la experiencia donde las atribuciones dejan de tener correspondencias y adquieren una lógica anómala" (2012: 173).
} 
desencadena instintos y pulsiones sin freno ni distinción. El hambre no se presenta como un atavismo, no es que sea una vuelta atrás de la especie, es una necesidad elemental y primaria. Si lo animal formó parte de lo que la cultura civilizatoria reprimió pasa asegurar el vínculo humano (tal cual la domesticación de los perros), el neoliberalismo no solo desposee materialmente, sino que desregula este ordenamiento, de ahí la trama del cuento: comer, devorar, colmar, fornicar, matar.

"No soy yo, es mi cuerpo el que amamanta a la Negra" (2009: 221), dice la protagonista en el momento decisivo en que se separa de su silueta corporal y se convierte en pura materia viviente, nutricia, violentada, naturalizada, en un lugar imposible de enunciación, de un bios desplazado a zoé. Este es el estado que narra el cuento de Meruane, a la inversa de Lugones o Conti, un proceso de desubjetivación como efecto devastador del poder tanatopolítico, efectivo en su manera de hacer vivir y dejar morir. A diferencia de Barreto, no neutraliza la "máquina antropológica" sino que muestra la violencia con la que operan sus cesuras.

El relato transcurre en una interioridad doméstica ("la pieza" la llama la narradora). Afuera, un exterior de tiendas, calles y servicios asoma, espacios que proveen de alimentos y salud por los que la protagonista pasa y por los que sabemos de su precariedad. Pero en esos lugares rigen también intercambios anómalos entre cuerpos y formas de vida. En el hospital, la protagonista huye sin probar el desayuno ante la amenaza de que le retiren a su bebe: "Tampoco alcancé a probar el desayuno que me trajeron. Dejé la bandeja sin tocar, tenía que zafarme de las matronas que pedían mi nombre, que exigían más información sobre mi situación familiar. Miraban a mi criatura con hambre maternal. Debí arrancárselas de los brazos" (2009: 223); la calle es el lugar de exhibición y explotación del cuerpo femenino, remarcado en cursivas: "En esa gordura se clavan las miradas de los hombres y ahi se quedan" (2009: 222). Incluso el gesto caritativo de la tendera, que le regala provisiones, se reviste de culpa; "La dueña me preguntó si ya había expulsado a la criatura, si estaba todavía en el hospital, a quién se la había dejado. ¿Durmiendo con la perra?, me preguntó haciendo una extraña mueca de desamparo y a continuación, en vez de fiarme el pan me lo regaló" (2009: 223). La "pieza" no resguarda de ninguna exclusión, solo la lleva más adentro, a un interior animal que habita en la ciudad y que se esconde en sus entrañas.

¿Qué emerge en esta ficción animal? La resistencia en una zona indeterminada de lo viviente en donde la desposesión linda con la abyección. Lo que el hambre viene a violentar, aquello que "rompe, destroza, corta, quiebra" (Barreto 2014: 308). Un "hambre perra", según apunta el título, que termina con las especies porque difícilmente se puede sobrevivir a ella. Una manera de vivir que convencionalmente hemos llamado animal en el olvido de nuestra naturaleza o a su costa. Un modo de "morir como un perro" que no dista ni de matarlo ni de vivir como tal, con lo que la comparación no se funda en la semejanza sino en la absoluta equivalencia de sus términos. En ese sentido, la voz narrativa traspasa un umbral para encarnar literalmente esta expresión. Emerge entonces una lengua inhumana que ensaya con la dimensión animal de la vida precaria, esto es, que pone a prueba los límites del lenguaje y de la vida politizada. 
En el recorrido de mi exposición, que arrancaba a comienzos del siglo pasado, el animal tomaba cuerpo en el personaje de "Yzur" de Lugones. Su presencia requería de corporalidad física para contraponer con exactitud la vida humana del científico. El cuerpo del mono encarnaba el sometimiento al poder de su amo quien, respaldado por la superioridad que le otorgaban el lenguaje y la ciencia, lo conducía a una segura explotación truncada por la muerte. La violencia de la "máquina antropológica” (Agamben 2006: 69-76) decidía aquí la separación entre lo humano y lo animal, la jerarquía que rige su dominio, la vulnerabilidad de ciertas vidas.

La silueta del cuerpo animal se desdibuja en las obras contemporáneas de Conti, Barreto y Meruane al disolver la contención defensiva o la alteridad estructural que fundamenta esta máquina. En Conti, la figura del león se plantea como una forma poética de imaginación política y una expectativa de vida que escapa a los límites de la precariedad de su protagonista. El giro de este relato inaugura una retórica de la pobreza que implica un desplazamiento de las cesuras tan persistentemente fijadas por Lugones. Un giro que el poemario de Barreto explorará en su dimensión lingüística y biopolítica al reconocerse habitado por el animal y al cantar el duelo por la muerte de un caballo. La muerte del animal perfila en esta ocasión tanto el hambre como condición de la vida precaria como la distinción entre vidas dignas de reconocimiento jurídico y vidas carentes de él. A su vez, esta poética se abre expansivamente a la posibilidad de revertir la vulnerabilidad que ha dejado al descubierto la ausencia del caballo para hacer de ella un común de lo viviente, fuera de la designación biopolítica que lo captura. Las consecuencias extremas de esta captura se narrativizan en "Hambre perra" de Lina Meruane, en donde el cuerpo humano se entrelaza con el animal y en donde el hambre feroz termina por recordarnos en nombre de qué humanidad y de qué vida estamos hablando.

\section{Obras citadas}

Agamben, Giorgio. 2006. Lo abierto. El hombre y el animal. Buenos Aires: Adriana Hidalgo Editora. . 2010. Homo sacer. El poder soberano y la nuda vida. Valencia: Pre-Textos.

Auyero, Javier. 2007. "Introducción. Claves para pensar la marginación”. En Louis Wacquant, Parias urbanos. Marginalidad en la ciudad a comienzos del milenio, Buenos Aires: Manantial. 9-32.

Barreto, Igor. 2014. El campol El ascensor, poesía reunida (1983-2013). Madrid-Valencia: Pre-Textos.

Butler, Judith. 2006. Vida precaria. El poder del duelo y la violencia. Buenos Aires: Paidós. 2010. Marcos de guerra. Las vidas lloradas. Buenos Aires: Paidós.

Conti, Haroldo. 2003. Cuentos completos. Buenos Aires: Emecé.

Derrida, Jacques. 2008. El animal que luego estoy si(gui)endo. Madrid: Trotta.

Esposito, Roberto. 2009. Tercera persona. Politica de la vida y filosofía de lo impersonal. Buenos Aires: Amorrortu. 
Forcadell, María. 2009. Representaciones e imaginarios sobre la pobreza: Villa miseria y subjetividad en la literatura argentina del siglo XX y XXI. [Tesis doctoral inédita]. Washington University in St. Louis: Saint Louis.

Foucault, Michel. 1987. Historia de la sexualidad I. La voluntad de saber. México: Siglo XXI. . 2000. Defender la sociedad. Curso en el Collage de France (1975-1976). Buenos Aires: Fondo de Cultura Económica.

Giorgi, Gabriel. 2014. Formas comunes. Animalidad, cultura, biopolitica. Buenos Aires: Eterna Cadencia.

Lugones, Leopoldo. 1987. Cuentos fantásticos. Madrid: Castalia.

Meruane, Lina. 2009. "Hambre perra". Nuestra América. Revista de Estudios sobre la Cultura Latinoamericana 7: 121-124.

Ramos, Julio. 1996. Paradojas de la letra. Caracas: Ediciones eXcultura.

Saítta, Sylvia. 2006. "La narración de la pobreza en la narrativa argentina del siglo xx". Nuestra América. Revista de Estudios sobre la Cultura Latinoamericana 2: 89-102.

Saraceni, Gina. 2012. "La intimidad salvaje. El grado animal de la lengua". Voz y escritura. Revista de Estudios Literarios 20: 163-179.

Sarlo, Beatriz. 1988. Una Modernidad periférica: Buenos Aires 1920 y 1930. Buenos Aires: Nueva Visión.

Yelin, Julieta. 2015. La letra salvaje. Ensayos sobre literatura y animalidad. Rosario: Beatriz Viterbo Editora. 